\title{
Briefings, Checklists, Geese, and Surgical Safety
}

\author{
Richard Karl, MD, FACS \\ Department of Gastrointestinal Oncology, Moffitt Cancer Center, Tampa, FL
}

The successful landing in the Hudson River by a commercial jetliner after both engines were rendered inoperative by striking a flock of Canada geese commandeered the news cycle worldwide. Two weeks later, a report appeared in the New England Journal of Medicine demonstrating that the use of a simple surgical safety checklist could decrease mortality and morbidity after surgical procedures in a global population.

These two seemingly unrelated events occurring in January 2009 make clear the differences in regards to safety when medicine in general, and surgery in particular, are compared with commercial aviation. Reports published after the airplane incident, in which all 155 passengers and crew survived, make it clear that the crew members of US Airways followed prescribed procedures and communication techniques as they guided the powerless aircraft to a safe outcome. Though both pilots were highly experienced and though the copilot was flying the airplane when the bird strike occurred, they followed the standard practice of returning aircraft control to the captain in an emergency. "My aircraft," said Captain Chesley Sullenberger. "Your aircraft," replied first officer Jeff Skiles. ${ }^{1}$ Both had practiced this transfer of command in the company's simulator training center in Charlotte, $\mathrm{NC}$, many, many times.

As the airliner, now a glider, fell from the sky, Captain Sullenberger maintained airspeed and situational awareness, and called for the dual engine flameout checklist. As first officer Skiles worked his way through the engine restart checklist (designed for use at higher, much higher altitudes), Sullenberger broke a conventional rule by doing the radio work while flying the airplane. His calm voice has been heard around the world; the only hint to the

(C) Society of Surgical Oncology 2009

Published Online: 10 November 2009

R. Karl, MD, FACS

e-mail: richard.karl@moffitt.org immediacy of the problem of trying to save 155 lives, including his own, was his use of an incorrect flight number.

What is so surprising is the disparity between aviation's routine use of simulator training, line-oriented safety audits, check airmen, crew resource management, proficiency checks, callouts, read-backs, briefings, and checklists and surgery's inexplicably slow efforts to embrace these useful safety tools. The fact that an elementary checklist's efficacy would warrant publication in one of our most prestigious journals signals how far we have to go to match the kinds of safety techniques viewed as commonplace and unremarkable in nuclear power, navy carrier, and submarine operations and in commercial aviation.

Though we in surgery have been slow to adopt many of the safety techniques characteristic of high-reliability industries, evidence is now beginning to appear that what we have borrowed has worked. The checklist program mentioned above introduced a 19-item checklist designed to improve team communication in eight hospitals around the world. As part of the World Health Organization's Safe Surgery Saves Lives Program, the authors found that the use of checklists resulted in a significant decrease in mortality $(1.5 \%$ before institution of the checklist, $0.8 \%$ afterwards, $p=0.003$ ) and morbidity (11.0\% before, $7.0 \%$ after, $p<0.001)^{2}$

Investigators using checklists as prompts for preoperative briefings measured communication failures in a large Canadian tertiary care hospital. The found that the mean number of communication failures per procedure decreased from 3.95 to 1.31 after initiating briefings and checklists. ${ }^{3}$ Thirty-four percent of briefings demonstrated effectiveness in identifying problems, resolution of critical knowledge gaps, and decision-making.

Checklists are used routinely and habitually by airline personnel and sporadically by surgical workers. In the airlines and military, checklists are viewed as another 
member of the crew. They are living, evolving instruments. Checklists are not "to do" lists. They are methodical reminders to be sure that important procedures have been successfully carried out. "Challenge, verify, and response" is the critical construction format to aviation checklists, but is not routinely or even often used in medicine.

Briefings are central to safe airline flight. Several, not just one, are routinely done prior to, during, and after a flight. There are first flight of the day briefings, pre-start briefings, taxi briefings, pre-takeoff briefing, approach and landing briefings, and post-flight debriefings. These multiple communication events are short, patterned, and expected.

In surgery, we have a brief moment referred to as "timeout." This word sounds like a break in the action, as if we are unsafe most of the time and take a break to be safe. In aviation, safety is woven into the fabric of flight. A study from Johns Hopkins in which standardized preoperative briefings were instituted found a $36 \%$ decrease in unexpected delays $(p<0.04)$. Among surgeons alone, an $82 \%$ decrease in delays was found $(<0.01) .{ }^{4}$ The authors concluded that this safety initiative has the potential to increase safety, decrease delays, and improve hospital profitability. In another publication from the same institution, the briefings program significantly reduced the perceived risk for wrong-site surgery and improved collaboration among operating room personnel. ${ }^{5}$

High-reliability organizations typically seek workers with emotional intelligence in addition to task-specific abilities, a factor not often considered when selecting surgical personnel. Nonetheless, studies of surgical team behaviors are starting to appear. In one study behavioral markers of team behavior (information sharing, inquiry, vigilance, awareness, assertion, and contingency management) were assessed by observers and compared with patient outcomes. In univariate analysis, patients had increased odds of complications or death when the following behaviors were exhibited less frequently: information sharing during intraoperative phases and handoffs, and briefing during handoffs. Composite measures of teamwork across all operative phases were significantly associated with complication or death after adjusting for American Society of Anesthesiologists (ASA) scores (odds ratio 4.82, 95\% confidence interval). ${ }^{6}$

A similar conclusion was reported in a study based in a large Veterans Affairs (VA) hospital and academic medical center. Surgical teams whose members reported higher levels of communication and collaboration with the attending and resident doctors had decreased risk-adjusted morbidity. ${ }^{7}$ The authors found this fact not surprising in light of the fact that poor communications have been cited most frequently as a root cause of sentinel events reported to the Joint Commission for the Accreditation of Health Care Organization. ${ }^{8}$

Though checklists and briefings appear to be effective in surgical settings, other safety techniques used in aviation, nuclear power, and the navy have been marginally effective. Many other techniques have not been evaluated at all. ${ }^{9}$

Crew resource management programs, often invoked by health care institutions intent on improving safety, have had mixed success when implemented as a standalone intervention. At one institution a team training program resulted in "moderate compliance" by operative teams. No changes in hospital metrics were observed..$^{10}$ At another, an ambitious crew resource management program modeled after aviation produced low compliance rates with simple tasks such as site marking and an adequate "timeout." 11

The paucity of literature about surgical safety and the modest achievements of early attempts to apply techniques that are very successful in other high-reliability professions provoke this question: "What do we need to do to become safe?"

The answer lies in a quote from human factors expert James Reason, who, while addressing the Royal College of Surgeons, said, "Aviation is predicated on the assumption that people screw up. You (healthcare professionals) on the other hand, are extensively educated to get it right and so you don't have a culture where you share readily the notion of error. So, it is something of a big sea change." 12

Cultural change, it appears, is more difficult than team training and takes longer than checklist implementation to become effective. ${ }^{13}$ The good news is that it does not require the discovery of a gene or the investment of large sums of money in computer hardware and software. A variety of hiring, training, and recurrent assessment techniques used in aviation may be useful in surgery if the entire package is implemented rather than in fragments. What follows are aviation programs that are not, as yet, mirrored in our surgical world.

\section{NEW HIRES AND ORIENTATION}

Hiring of pilots at major airlines is done in a codified fashion and often includes a scenario in a "cockpit trainer" to evaluate leadership skills of the potential hire. In surgery, letters of recommendation, an unstructured interview, and a dinner at a local restaurant are the commonplace methods of assessing the suitability of new faculty. Once hired, airline pilots undergo a lengthy (6-8 weeks) orientation to the airline's procedures, policies, culture, and history. In medicine, our orientation programs tend to be more formulaic and short. Once the $401 \mathrm{k}$ is established and the doctor is credentialed, little effort is made to ensure a culture of safety and quality. ${ }^{9}$ 


\section{INITIAL OPERATING EXPERIENCE}

Newly hired pilots or pilots upgrading to captain undergo $25 \mathrm{~h}$ of Federal Aviation Administration (FAA) mandated initial operating experience (IOE) or upgrade operating experience (UOE). During this period of time the pilot is tutored and evaluated by a "check airman," who has been trained to fly with the pilot, provide nuanced useful operating information, and evaluate the pilot in his or her new role. In most surgical departments fully trained board-eligible newly hired surgeons are given operative privileges and left unsupervised. They are not evaluated for skill, adherence to hospital policies, or commitment to safety. We do not often make an effort to instruct the new physician as to how we do it here and why we do it this way. Our cultures are confusing and often at cross purposes. Is my job to generate revenue, get grants, teach or be safe?

\section{THE ROLE OF SIMULATORS AND RECURRENT TRAINING}

Recurrent simulator training and ground school are an integral part of commercial aviation. Captains return to training centers every 6 months, where they are informed of new policies and the collective experience of others flying the same routes, and are evaluated for their flying skills. In surgery, new maintenance of competency policies are on the horizon, but not yet implemented in a way that reflects the level of commitment seen in commercial aviation.

\section{BEING SAFE VERSUS DOCUMENTING SAFETY}

A major cultural difference between aviation and medicine is our emphasis on documentation rather than safe performance of a task. Thus, a nurse is frequently typing during the "timeout" rather than ensuring that information is accurate. No pilot is asked to fill out a form proving that she checked the landing gear position prior to landing. The checklist is there to be certain the wheels are down, not documented to be down.

\section{DECISION SUPPORT}

Surgeons are expected to deal with various emergencies by memory, whereas most in-flight emergencies are handled by reference to a "quick reference handbook." In this book, one finds the appropriate algorithms to follow for dual engine failure, engine fire, sudden depressurization, etc. Most operating rooms have no handy reference materials to guide surgeons, nurses, technologists, and anesthesia personnel when something unexpected occurs. Treatments for bradycardia, for example, are highly individualized based on staff experience and knowledge.

Airlines are designed to function when some equipment is inoperative. A "minimum equipment list" contains the rules for deciding whether a flight can continue or begin with, say, an auxiliary power unit generator malfunctioning. In surgery, most equipment, supply, and environment decisions are left to the discretion of the surgeon, who may never have contemplated the consequences of starting an operation without blood available until an unusual antibody is detected and the consequences become all too clear.

\section{FATIGUE, DRUGS, AND ALCOHOL}

Duty hours for airline pilots are $14 \mathrm{~h}$ on duty and $8 \mathrm{~h}$ of flying per day. Rest periods between duty hours are strictly prescribed. Random drug and alcohol testing is an industry standard. In surgery, with the exception of the 80-h work week for resident staff, no mandatory rest periods or routine screening for performance-impairing substances are in effect. However, there is ample evidence that sleep deprivation has a similar effect on cognitive and motor function to that of intoxication by alcohol. ${ }^{14}$

\section{SAFETY REPORTING SYSTEMS}

No-fault reporting systems are frequently used in aviation. The aviation safety action program (ASAP) is widely held to be successful. Interestingly, it is administered by the National Aeronautics and Space Administration (NASA), not by the FAA, and has the mechanisms to preserve reporter anonymity. Though many hospitals have some type of reporting system, most clinicians are unaware of them and infrequently contribute near-miss information. There is no national/government body that administers a no-fault program. For that matter, there is no national equivalent of the Federal Aviation Administration.

\section{NO DISTRACTIONS}

Below 10,000 ft, all airline operations are under "sterile cockpit rules." No discussion other than that pertinent to the safe conduct of the flight is permitted. Compare this to most operation rooms, where irrelevant discussions and distractions are frequently entertained even during the most critical portion of the procedure. I know from unhappy personal experience that it is during these times that inadvertent mistakes can be committed, sometimes with disastrous consequences. ${ }^{9}$

Though by no means exhaustive, these examples of disparity between aviation and surgery make clear that, as 
surgeons, we have just begun to understand the causes of error and to make progress in our ability to prevent and mitigate error. Recently, Pronovost et al. suggested that, given the slow progress of patient safety, a public-private partnership be established to move quality and safety forward in medicine. The model proposed is similar to the Commercial Aviation Safety Team (CAST) established in the wake of aircraft accidents in the $1990 \mathrm{~s}$. In these accidents, fully functioning airplanes were lost due to factors such as loss of situational awareness, poor crew communication, and failure of some crew members to be assertive to imperious captains. CAST brought the entire aviation industry together; major manufacturers, airlines, unions, the National Transportation Safety Board (NTSB), the FAA, the Department of Defense (DoD), and NASA. From 1994 to 2006, the average rate of fatal accidents decreased from 0.05 to 0.022 per 100,000 departures. ${ }^{15}$

The challenge now is to recognize that medical error costs lives and to do something about it. The Institute of Medicine concludes that we kill as many as 100,000 patients a year in the USA alone. ${ }^{16}$ The Institute for Healthcare Improvement calculates that 15 million "incidents of harm" occur in our health care system each year. ${ }^{17}$ These wrong-site operations and retained surgical items, among other things, are avoidable events. When they occur they harm not only the patient and the reputation of our profession, but they harm us, as surgeons, as well; no surgeon gets up in the morning with the intent of hurting another human being in the course of trying to set right what nature has made wrong. We now need to adopt and develop systems to curtail error and to protect ourselves and our patients.

\section{REFERENCES}

1. Kolker R. My aircraft. New York Magazine. Feb 1, 2009.
2. Haynes A, et al. A Surgical safety checklist to reduce morbidity and mortality in a global population. $N$ Engl $J$ Med. 2009;360:491-9.

3. Lingard L, et al. Evaluation of a preoperative checklist and team briefing among surgeons, nurses, and anesthesiologists to reduce failures in communication. Arch Surg. 2008;143(1):12-7.

4. Nundy $S$, et al. Impact of preoperative briefings on operating room delays. Arch Surg. 2008;143(11):1068-72.

5. Makary M, et al. Operating room briefings and wrong-site surgery. J Am Coll Surg. 2007;204:236-43.

6. Mazzocco K, et al. Surgical team behaviors and patient outcomes. Am J Surg. 2009;197(5):678-85.

7. Davenport D, et al. Risk-adjusted morbidity in teaching hospital correlates with reported levels of communication and collaboration on surgical teams but not with scale measures of teamwork climate, safety climate, or working conditions. J Am Coll Surg. 2007;205:778-84.

8. The Joint Commission for the Accreditation of Health Care Organizations. Root cause statistics. Accessed April 13, 2009.

9. Karl R. Aviation. J Gastrointest Surg. 2008;13:6-8.

10. Halverson A, et al. Surgical team training. Arch Surg. 2009;144(2):107-12.

11. France D, Leming-Lee S, Jackson T, Feistrizer N, Higgins M. An observational analysis of surgical team compliance with perioperative safety practices after crew resource management training. Am J Surg. 2008;195(4):546-53.

12. Reason J. Human error: models and management. $\mathrm{Br}$ Med J. 2000;320(7237):768-70.

13. R. Karl. Staying safe: simple tools for safe surgery. Bull Am Coll Surg. 2007;92(4):16-22.

14. Dawson D, Reid K. Fatigue, alcohol, and performance impairment. Nature. 1997;388.

15. Pronovost P, et al. 2009 Reducing health care hazards: lessons from the commercial aviation safety team. Health Affairs. 28(3):479-89.

16. Kohn LT, Corrigan JM, Doandlson MS, eds. To err is human: building a safer health system. Committee on Quality of Heath Care in America. Institute of Medicine. Washington, DC: National Academy; 2000.

17. IHI launches national campaign to reduce medical harm in U.S. hospitals, building on its landmark 100,000 Lives campaign. Accessed April 13, 2009. 